\title{
Indígenas no espaço urbano e particularidades do Nordeste
}

\author{
Indigenous peoples in the urban space and norde's particularities
}

\author{
Elizângela Cardoso de Araújo Silva* \\ Codjo Olivier Sossa**
}

\begin{abstract}
Resumo: No contexto das expressões da questão urbana no Brasil, a desigualdade, o desemprego e acesso à renda atingem as famílias indígenas que vivem nas cidades. Neste artigo são dos dados das condições sociais da vida indígena no contexto urbano da região Nordeste, levantados e analisados por um Estatístico do povo Adja (Benin, África) e uma Assistente Social, indígena do povo Pankararu (Brasil, América do Sul). As análises resultam do levantamento documental, bibliográfico associado a elementos de relato de experiência dos autores deste artigo. Constata-se a existência de elementos que caracterizam situações de empobrecimento indígena no contexto urbano no Nordeste do Brasil e demandas por ações de políticas sociais.
\end{abstract}

Palavras-chave: Indígenas; Espaço Urbano; Nordeste.

Abstract: In the context of expressions of the urban issue in Brazil, inequality, unemployment and access to income affect indigenous families living in cities. In this article, data from the social conditions of indigenous life in the urban context of the Northeast region are collected and analyzed by a statistician from the Adja people (Benin, Africa) and a Social Worker, indigenous from the Pankararu people (Brazil, South America). The analyzes result from the documentary, bibliographic survey associated with elements of the experience report of the authors of this article. It is noted the existence of elements that characterize situations of indigenous impoverishment in the urban context in Northeast Brazil and demands for social policy actions.

Keywords: Indigenous; urban space; Northeast.

\footnotetext{
* Indígena do povo Pankararu, Pernambuco. Doutoranda em Serviço Social pelo Programa de Pós Graduação em Serviço Social da Universidade Federal de Pernambuco (UFPE), Pernambuco, Brasil. Membro do Núcleo de Estudos e Pesquisas sobre Questão Ambiental e Serviço Social (NEPASS) do Curso de Serviço Social da UFPE.

** Pertencente ao povo da etnia Adja, Benin, África. Graduado em Estatística, Mestre em Economia/PIMESUFPE.Doutorando em Estatística-PPGE/UFPE.
} 


\section{Introdução}

Este texto tem como objetivo apresentar tendências e as características das condições sociais de vida de indígenas que vivem na área urbana no Brasil, destacando as particularidades do Nordeste. A metodologia está baseada em pesquisa documental e bibliográfica, associada a elementos de relato de experiência.

O texto analisa dados da região Nordeste e tem como principal fonte de dados, o Censo de 2010 do Instituto Brasileiro de Geografia e Estatística (IBGE), contando de forma pontual e complementar com reflexões resultantes de dois documentários sobre indígenas que vivem na cidade. Os documentários são citados contribuem com entendimento desse fenômeno em outras regiões do Brasil.

A presença indígena no contexto urbano é um desafio para os povos indígenas e para a sociedade brasileira, considerando as desigualdades que afetam a presença de indígenas nas cidades e o reconhecimento tardio das garantias do Estado brasileiro do direito à diferença e ao respeito étnico dos povos originários. A vida indígena na cidade em particular, pode representar viver fora dos territórios tradicionais de origem, e/ou desvinculados dos grupos étnicos que pertencem.

Como representação dessa realidade, o caso específico de famílias indígenas Pankararu, residentes na cidade na região do Sertão do estado de Pernambuco ${ }^{1}$, vive-se processos de saída das aldeias, e posteriormente, da margem do São Francisco por meio de remoções compulsórias. Esse movimento de deslocamento marca a presença das gerações de idosos, adultos, jovens e crianças Pankararu no contexto urbano. A vida na cidade depara-se com dificuldades nas relações sociais e de trabalho, considerando a tendência do não acesso das gerações indígenas mais velhas ao ensino escolar e educação para o mercado de trabalho.

No Brasil, a urbanização de territórios onde habitavam populações indígenas fez com que esses se tornassem trabalhadores assalariados de economias locais. É possível identificar essa realidade nos relatos das famílias Pankararu participantes da pesquisa da tese SILVA (2020), ao relatarem nas entrevistas a constante busca por atividades em troca de

\footnotetext{
${ }^{1}$ Caso analisado na tese de doutorado: SILVA, Elizângela Cardoso de Araújo. Indígenas Pankararu no sertão de Pernambuco: vida, deslocamentos e trabalho. Tese (Doutorado em Serviço Social) - Universidade Federal de Pernambuco, CCSA, 2020. 222 folhas: il. $30 \mathrm{~cm}$.
} 
salário e a realização de atividades de baixa remuneração, sem vínculos formais, temporárias, prestação de serviços pontuais².

São muitas as razões que levam os indígenas se deslocarem para as cidades. Sobre essa realidade em outros estados brasileiros, podemos citar o documentário Índios na cidade (2013). Observa-se situações semelhantes na vida de indígenas que vivem em outras regiões. No documentário produzido com depoimentos de indígenas de várias regiões do Brasil e residentes na grande São Paulo, é possível identificar que muitos indígenas migram para a cidade por necessidade de sobrevivência, de trabalho, de acesso a serviços básicos e melhores condições de vida, como: educação, saúde, moradia.

Nos relatos das famílias Pankararu como nos relatos de indígenas dos documentários sobressaem-se as características comuns, específicas de trabalhos e empregos dessa inserção na vida urbana. Joaquim Vicente de Paula, Chefe do IBGE de Roraima, em sua obra Índios na cidade (2013), ao citar as desigualdades históricas que atingem indígenas como o não acesso à educação escolar, o não acesso à qualificação profissional, o não acesso ao ensino superior trata desses determinantes como aqueles que levam indígenas a compor os indicadores de menor renda e menor escolaridade, os localizando nas piores condições de vida, de emprego e de trabalho entre povos indígenas.

A vida indígena dos participantes da pesquisa de Silva (2020) que vivem na cidade é marcada pelo não acesso à qualificação profissional, pela precária inserção da força de trabalho em diferentes setores da economia, em que desenvolvem atividades como: ajudantes, pedreiros, carpinteiros, auxiliares de serviços gerais, domésticas, vendedores do comércio local entre outros. Essa inserção, nas cidades é acompanhada de preconceitos que levam, em alguns casos, ao isolamento e ao adoecimento psíquico.

O Documentário: Índios na cidade, vidas em travessia (2014) apresenta diferentes possibilidades de organização social de indígenas no contexto urbano: organização de mulheres para o enfrentamento da violência contra a mulher; discussão sobre direitos sociais como moradia, educação, saúde e respeito étnico.

Destacam-se também, nos depoimentos dos indígenas entrevistados por SILVA (2020), em consonância com os indígenas de diferentes grupos étnicos no documentário, enfrentamentos da vida urbana, o desejo de viver a identidade étnica, a cultura, os vínculos espirituais com mais respeito, bem como, o direito ao acesso à educação escolar e

\footnotetext{
2 Realidade apresentada no documentário: Índios na cidade, vidas em travessia (2014).
} 
profissional como meio de construir habilidades e competências imprescindíveis para maior atuação política nos espaços de decisão sobre as políticas indigenistas e melhores condições de vida na cidade.

\section{Presença indígena no nordeste e condições de vida na cidade}

A particularidade das desigualdades sociais que afetam a vida indígena no Nordeste do Brasil requer situá-la na história da ocupação territorial e organização da produção econômica no Brasil desde a colonização. Ou seja, as origens da divisão da terra, dos conflitos, as formas de usos que levaram os indígenas dessa região ao amplo processo de mistura e reconfiguração das identidades territoriais e étnicas.

$\mathrm{Na}$ realidade dos povos indígenas do Nordeste Brasileiro existem movimentos de deslocamento individuais e coletivos que implicam novas formas de reagrupamento. Podemos citar a experiência da rede de parentesco da nossa autoria Pankararu, deslocamentos coletivos de famílias indígenas no estado de Pernambuco que se destacam a partir da construção de barragem e usina hidrelétrica no sertão de Pernambuco ${ }^{3}$.

Sobre deslocamentos coletivos muito comuns entre indígenas Pankararu, especialmente décadas de 1970 e 1980 podemos destacar os "desaldeamentos" como saída compulsória das aldeias na direção de novos agrupamentos na área urbana ou novos agrupamentos em novas áreas rurais, permanecendo comum o deslocamento em grupos, com conexão de laços de parentesco. Pode também ocorrer a dispersão de indígenas em espaços urbanos por conta das diferentes ofertas/oportunidades de empregos.

No período colonial, os povos indígenas passaram por constantes processos de deslocamento coletivos forçados, o que fez nascer uma versão colonial de aldeamento. Isso significou a fixação de territórios para o controle dos "senhores", levando ao violento rompimento de muitos dos elementos culturais e sociais da condição originária.

Destaca Arruti (2017, p. 8) que no Nordeste - região de colonização mais antiga "todos os seus aldeamentos indígenas foram oficialmente extintos em um período de menos de 10 anos, entre as décadas de 1860 e 70".

\footnotetext{
${ }^{3}$ Caso específico analisado na tese de doutorado de: Silva, Elizângela Cardoso de Araújo. Tese de doutorado. Indígenas Pankararu no sertão de Pernambuco: vida, deslocamentos e trabalho. UFPE,Recife. Maio de 2020.
} 
Em decorrência da Lei de Terras de 1850, os estados da federação foram incumbidos de fazer o cadastramento de todas as terras devolutas existentes em seus territórios. Para isso foram instituídas Comissões de Medição e Demarcação, constituídas por engenheiros e cartógrafos, que içaram com a responsabilidade de avaliar, a partir de um conjunto restrito de itens (a incorporação no mercado de trabalho local, a existência de casamentos com brancos e a profissão da fé cristã), se os aldeados ainda eram indígenas se já haviam civilizado. A resposta das Comissões foi, invariavelmente, a constatação da civilidade dos aldeados (ARRUTI, 2017, p. 8).

Como assevera Arruti (2017), a avaliação de "indianidade" da Lei de Terras atuou significativamente para a reconfiguração dos agrupamentos indígenas, já que muitos grupos considerados "misturados" ou "civilizados", mesmo aldeados, deixaram de ser tratados como índios.

\begin{abstract}
Convertidos em população comum, de trabalhadores nacionais, suas terras foram incorporadas aos "próprios nacionais", parceladas e comercializadas. Enquanto os próprios aldeados foram dispersos ou acuados em pequenos trechos de seus antigos territórios, passando a ser proibidos de exercer algumas das práticas que os distinguiam. Entre essas, em especial o Toré, que - como também ocorreu com as práticas religiosas africanas - foi criminalizada e perseguida (ARRUTI, 2006, p. 51).
\end{abstract}

A imagem do "índio misturado" que representa essa mistura entre o indígena e não indígena, associada às interações culturais, sociais e econômicas que resultaram na imagem do "caboclo". Como também afirma Silva (2017, p. 123):

Os habitantes dos lugares onde existiram antigos aldeamentos passaram então a ser chamados de "caboclos", condição essa muitas vezes assumida pelos indígenas para esconder a identidade étnica diante das inúmeras perseguições (SILVA, 2017, p. 123).

A imagem do caboclo sobrepunha-se, apagando oficialmente as populações indígenas no Nordeste. Constatamos, até aqui, como o poder colonial imprimiu essa constante manipulação da vida indígena: invadindo, matando, escravizando, isolando, proibindo, obrigando o outro a "ser" e "agir" de acordo com o que garantisse a realização dos interesses econômicos e políticos do "agir" colonizador, da organização colonial.

Não se pode perder de vista as práticas de agrupamentos e assimilação forçados aos índios durante toda a colonização, um projeto civilizatório "integracionista" voltado à eliminação das diferenças, impôs mudanças nos modos de vida dos povos originários. O que também ocorre no Nordeste, por dentro da criação e manutenção dos aldeamentos, se deu o controle e a escravidão indígena como parte da organização da produção colonizadora até 
o século XVIII. "No século XVIII, a região [Nordeste] contava com mais de 60 aldeamentos, ocupados por cerca de 27 nações indígenas, oficialmente extintas até às vésperas de 1880" (ARRUTI, 2017, p. 8).

Porém, a extinção dos aldeamentos nesse período, não extinguiu os povos indígenas e a possibilidade de reagrupamento como formas de resistência nos sertões do Nordeste:

\begin{abstract}
Apesar da violência e antiguidade do processo de expropriação de tais grupos, esse último golpe [a extinção das aldeias], que marca a sua extinção oficial, foi fundamentalmente de caráter classificatório e jurídico. Por força de um conhecimento técnico que postulou a sua reclassificação de índios para caboclos, eles deixaram de ter a prerrogativa legal de estar sob a administração de missionários e de dispor de terras de uso comum dos aldeamentos (ARRUTI, 2017, p. 8).
\end{abstract}

A citação de Arruti nos remete ao discurso ainda muito presente na realidade brasileira, produto dos processos compulsórios de mistura com vistas à formação da "nova identidade" de nação brasileira, que envolvia: misturar e levar ao branqueamento para "limpar a raça". Ou seja, eliminar as diferenças e apagamento das identidades étnicas foi uma estratégia amplamente utilizada para acabar com grupos sociais considerado um obstáculo para o desenvolvimento da nação.

O número da população indígena no Nordeste, de acordo com os dados do IBGE (BRASIL, 2010), por localização em Unidades de Federação é de 232.739 indígenas $^{4}$, como mostra o quadro abaixo:

QUADRO 1 - POPULAÇÃO INDÍGENA REGIÃO NORDESTE por localização do domicílio e percentual nas Terras Indígenas, segundo as Grandes Regiões e Unidades da Federação - 2010

\begin{tabular}{|c|c|c|c|c|}
\hline \multirow{3}{*}{$\begin{array}{l}\text { Grandes Regiões e Unidades da } \\
\text { Federação }\end{array}$} & \multicolumn{4}{|c|}{ População indígena } \\
\hline & \multirow{2}{*}{ Total } & \multicolumn{2}{|c|}{ Localização do domicílio } & \multirow{2}{*}{$\begin{array}{c}\text { Percentual nas } \\
\text { Terras indígenas } \\
\text { (\%) }\end{array}$} \\
\hline & & $\begin{array}{l}\text { Terras } \\
\text { Indígenas }\end{array}$ & $\begin{array}{c}\text { Fora de Terras } \\
\text { indígenas }\end{array}$ & \\
\hline Nordeste & 232.739 & 106.142 & 126.597 & 45,6 \\
\hline Maranhão & 38.831 & 29.621 & 9.210 & 76,3 \\
\hline Piauí & 2.944 & -- & 2.944 & - \\
\hline
\end{tabular}

\footnotetext{
${ }^{4}$ Disponível em: <http://www.funai.gov>.
} 


\begin{tabular}{|l|r|r|r|r|}
\hline Ceará & 20.697 & 2.988 & 17.709 & 14,4 \\
\hline Rio Grande do Norte & 2.597 & --- & 2.597 & -- \\
\hline Paraíba & 25.043 & 18.296 & 6.747 & 73,1 \\
\hline Pernambuco & 60.995 & 31.836 & 29.159 & 52,2 \\
\hline Alagoas & 16.291 & 6.268 & 10.023 & 38,5 \\
\hline Sergipe & 5.221 & 316 & 4.905 & 6,1 \\
\hline Bahia & 60.120 & 16.817 & 43.303 & 28,0 \\
\hline
\end{tabular}

Fonte: BRASIL, Censo Demográfico $(2010)^{5}$.

No Nordeste, os estados com menor número de indígenas são: Piauí e Rio Grande do Norte, embora os dados ainda estejam desatualizados. Esses são estados onde o Movimento Indígena luta pelo reconhecimento e demarcação de suas terras.

No Brasil, a urbanização de territórios onde habitavam populações indígenas antes da colonização fez com que parte desses tornarem-se progressivamente trabalhadores assalariados em indústrias ou trabalhadores agrícolas de economias locais do final do séculos XIX e durante XX. É possível identificar elementos dessa inserção nessa realidade nos documentários: "Índios na cidade, vidas em travessia" (2014).

Ao adentrar na dinâmica do contexto urbano e transitar nas cidades em busca de responder às necessidades básicas de reprodução social, os indígenas que saem de seus territórios, enfrentam os problemas estruturais próprios da realidade urbana brasileira, como: o desemprego a segregação, pobreza, problemas ambientais, a violência, entre outros. Esses problemas envolvem a desigualdade urbana e as relações de classe, sociedade e Estado, como analisa profundamente, Vera Silva Telles (2010), no livro: "A cidade nas fronteiras do legal e do ilegal". Essa obra da Telles é um instrumento de pesquisa fundamental para entender as origens e configurações históricas da "pobreza urbana" que envolve uma complexidade de tratos temáticos relacionados ao trabalho, às carências de vida e resposta sociais elaboradas pelo Estado.

Telles (2010) também apresenta contribuições de análise sobre percursos de experiências de diferentes perfis urbanos, onde, a partir de recortes analíticos como: família, grupos étnicos, encontramos chaves para entender as condições de acesso à cidade e seus espaços "[...] a trama dos atores, as vírgulas, as modalidades de apropriação dos espaços e seus recursos" (TELLES, 2010, p. 18). A autora segue afirmando: "A cidade é feita de cruzamentos, de passagem, é atravessada por experiencias que se fazem justamente nos

\footnotetext{
${ }^{5}$ Dados da FUNAI, 2019. Disponível em: <http://www.funai.gov.br/index.php/indios-no-brasil/o-brasilindigena-ibge>.
} 
limiares de universos distintos, de seus pontos de conecção e das redes sociotécnicas que os atravessam e articulam em um mesmo plano de atualidade" (TELLES, 2010, p. 21).

De acordo com dados do IBGE (BRASIL, 2010), a população indígena urbana no Brasil está distribuída da seguinte forma, em termos de características demográficas: de 0 a 14 anos - 21,1\%; de 15 a 64 - 71,9\%; e de 65 anos ou mais - 7,0\%.

No que se refere à educação, ainda há muito que avançar:

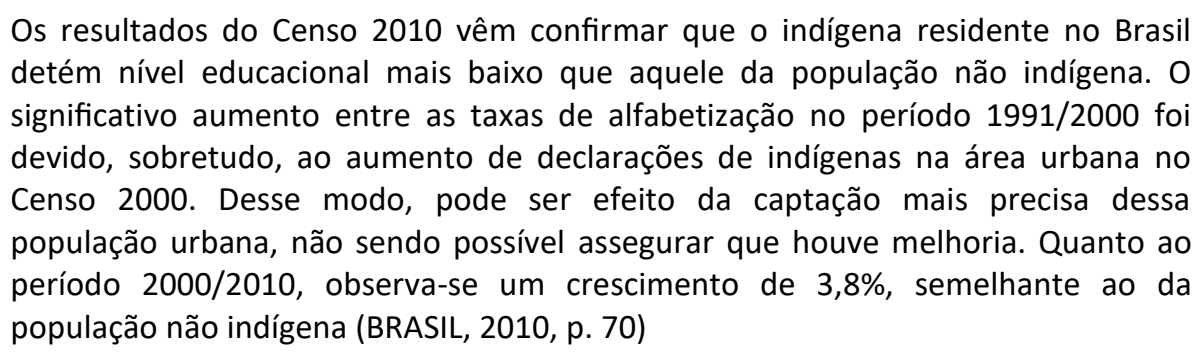

A educação escolar é um direito fundamental e uma possibilidade real de melhoria das condições de vida na cidade. A melhoria de indicadores de escolaridade é um elemento quantitativo muito importante para pensar qualitativamente em formas de participação social.

Porém, as relações sociais, a demanda ética de respeito à diversidade étnica é um desafio: respeito à língua ${ }^{6}$, à cultura, às crenças e às práticas espirituais dos indígenas ainda são um grande problema enfrentado nas escolas de ensino regular na área urbana, bem como no ensino superior e nas relações de trabalho. Persistem os riscos do apagamento cultural étnico dos povos originários que entram nessa dinâmica.

O acesso democrático ao ensino, à educação escolar pública e de qualidade no Brasil ainda é uma realidade distante. Embora nos últimos 30 anos, após a constituição Federal de 1988, que afirma o direito de acesso a uma saúde e uma educação diferenciadas para indígenas, essa realidade ainda requer estratégias para sua operacionalização.

Sobre a divisão por regiões, a população indígena está distribuída no Brasil da seguinte forma:

[...] o total de população indígena residente no território nacional passou a 896,9 mil pessoas [...]. Desses, $36,2 \%$ residiam na área urbana e $63,8 \%$ na rural. Enquanto na área urbana a Região Sudeste deteve o maior percentual de indígenas (80\%), a

\footnotetext{
${ }^{6}$ No Brasil existem 274 línguas indígenas faladas. O censo do IBGE (2010) demonstrou que 17,5\% da população indígena não fala a língua portuguesa. Disponível em: <http://www.funai.gov.br/index.php/indios-nobrasil/quem-sao>. Acesso em: 30 ago. 2018.
} 
Região Norte, com 82\%, foi o maior percentual da área rural. Pelos resultados do Censo Demográfico 2010, a Região Norte, com 342 mil indígenas, revela a sua importância como a mais populosa em indígenas no País. É explícita a dimensão dos grupos indígenas que habitam as terras indígenas, revelando $48,7 \%$ de indígenas em relação ao total de indígenas residentes no Território Nacional. A maior parcela de indígenas residentes fora das terras indígenas, em termos absolutos, correspondeu à Região Nordeste, com 126 mil indígenas, com um peso relativo de 33,4\% (BRASIL, 2010, p. 54).

Como podemos identificar no Censo do IBGE, há uma presença significativa de indígenas distribuídos em todo o território urbano do país (36,2\%). A região Nordeste é a que detém maior percentual de indígenas fora de terras indígenas, 33,4\%. Este dado "fora das terras indígenas" pode indicar muitas situações: a presença de indígenas em terras não demarcadas; pode significar habitantes de regiões urbanas e/ou rurais em processo de reivindicação de reconhecimento e demarcação, ou indígenas distantes de seus grupos étnicos, vivendo nas cidades, construindo novos territórios.

Importante ressaltar que "Território Indígena" é um conceito diferente de "Terra Indígena". O território é um espaço cultural e geográfico habitado por um grupo social com lógica interna de organização social (OLIVEIRA, 1993, p. 10). Indígenas estão distribuídos (separados ou junto do seu grupo étnico) em diferentes territórios que (ainda) não são tratadas juridicamente/oficialmente como Terras Indígenas (TI)

\begin{abstract}
No Nordeste existem 208.691 indígenas, segundo dados do IBGE (2010) ${ }^{8}$. Os povos indígenas no Nordeste lembram em suas tradições orais que com as invasões sistemáticas de suas terras e decretação das extinções dos aldeamentos, ocorreram casos de umas poucas famílias que migraram para terras de outros aldeamentos, também oficialmente declarados extintos. Muitas famílias indígenas engrossaram o grande contingente de mão de obra espalhado pelas regiões vizinhas às aldeias, ora trabalhando nas fazendas, como moradores, agregados, sem terras, ora trabalhando no cultivo sazonal da cana-de-açúcar na Zona da Mata, ora vagando pelas estradas, sem terras e sem tetos vieram ocupar as periferias dos centros urbanos (SILVA, 2003, p. 4).
\end{abstract}

O processo intenso de deslocamentos dos indígenas no Brasil e no Nordeste ainda é um desafio para a sistemática sobre quantos e quais as reais condições na área urbana por estado.

\footnotetext{
${ }^{7} \mathrm{TI}$ - Terras Indígenas identificadas, delimitadas, demarcadas, homologadas pelo Estado brasileiro a partir de processos administrativos realizados pelo órgão oficial responsável pela proteção dos direitos indígenas no Brasil - FUNAl a partir da organização e das reivindicações dos povos indígenas. De acordo com o Censo do IBGE (BRASIL, 2010), 57,7\% dos indígenas no Brasil moram em TI. Sobre modalidades de TI e processos administrativos de demarcação, consultar o site da Fundação Nacional do Índio, disponível em: $<h t t p: / / w w w . f u n a i . g o v . b r / i n d e x . p h p / i n d i o s-n o-b r a s i l / t e r r a s-i n d i g e n a s>$.

${ }^{8}$ Distribuição da população indígena no Brasil, disponível em: <http://www.funai.gov.br/index.php/indios-nobrasil/quem-sao>. Acesso em: 30 ago. 2018.
} 
Apresentamos nos tópicos que seguem alguns indicadores das condições de vida indígena no Nordeste contemporâneo, destacando dados de educação e de renda.

\section{Pobreza, educação e renda de indígenas no nordeste ${ }^{9}$}

A pobreza como fenômeno multidimensional atinge uma grande parcela da população brasileira. Falar de pobreza indígena é levar em consideração as particularidades e diferenças entre a vida urbana e a vida nativa no campo e os modos de vida autônomos, originários não capitalistas.

Significa levar em consideração que as sociedades indígenas no Brasil representadas pelas 305 etnias são muito diversas. Constroem e reconstroem culturas, costumes e práticas políticas e de produção, manuseio dos bens necessários à reprodução da vida por modos muito peculiares em seus territórios.

Desse modo, a categoria pobreza aqui apresentada está situada de forma muito específica. A escolha dos autores remete à explicação teórica específica das condições precárias de vida de populações indígenas que vivem no campo, e na cidade nos casos dos que já convivem com modos de vida tipicamente capitalistas, passando a adentrar em redes de assalariamento (força de trabalho livre, disponível no mercado de trabalho).

A condição de vida indígena na área urbana e os índices de precariedade da vida indígena na região Nordeste são resultado da condição histórica de uma das primeiras regiões do país onde a exploração econômica colonizadora ocorreu por mais tempo; destaca-se também a própria condição regional que o Nordeste assume com o fim do período colonial: disponibilizando força de trabalho "livre" para o avanço da indústria em outras regiões do país, como o caso dos parques industriais na Região Sudeste do país.

Dito isso, a pobreza é um fenômeno abordado por diferentes perspectivas e linhas teóricas. As análises da pobreza apresentam este fenômeno em várias dimensões, a saber: monetária, subjetiva, privação em termos de necessidades básicas, aspectos sociais e culturais. Partindo de uma abordagem puramente fisiológica, passamos para uma compreensão mais global que reconhece que as necessidades individuais e a interação na sociedade não dependem apenas do nível de consumo de alimentos que garantem a

\footnotetext{
${ }^{9}$ Este tópico compõe, em parte as análises do Capítulo 5 da tese SILVA, (2020). Capítulo que contou com a participação colaborativa na elaboração e sistematização de dados pelos dois autores deste artigo.
} 
sobrevivência biológica. Portanto, a pobreza pode ser considerada, em diferentes níveis (relativa, absoluta), como ausência, a exclusão de determinados grupos populacionais a bens materiais e não materiais necessários à continuidade da vida humana (cf. YAZBEK, 2009).

\begin{abstract}
A noção de pobreza é ampla, ambígua e supõe gradações e embora seja uma concepção relativa, dada a pluralidade de situações que comporta. Usualmente vem sendo medida por meio de indicadores de renda e emprego [...], ao lado do usufruto de recursos sociais que interferem na determinação do padrão de vida, tais como saúde, educação, transporte, moradia, aposentadoria e pensões, entre outros. Os critérios, ainda que não homogêneos e marcados pela dimensão de renda, acabam por convergir na definição de que são pobres aqueles que, de modo temporário ou permanente, não têm acesso a um mínimo de bens e recursos, sendo, portanto, excluídos, em graus diferenciados, da riqueza social. Entre eles estão: os privados de meios de prover à sua própria subsistência e que não têm possibilidades de sobreviver sem ajuda; os trabalhadores assalariados ou por conta própria, que estão incluídos nas faixas mais baixas de renda; os desempregados e subempregados que fazem parte de uma vastíssima reserva de mão de obra que, possivelmente não será absorvida (YAZBEK, 2009, p. 73).
\end{abstract}

O caráter multidimensional da pobreza, considerado como essencial para definir a condição de pobreza o acesso a alguns bens, de modo que sem esses os indivíduos e suas famílias não são capazes de usufruir de uma vida minimamente digna. Incluem: água potável, rede de esgoto, coleta de lixo, acesso ao transporte coletivo, educação, saúde e moradia, leva à necessidade de indicadores que tenham uma correspondente abordagem multidimensional e que levem em consideração como o indivíduo percebe sua situação social.

A análise da pobreza, do ponto de vista da condição de vida do povo indígena que mora fora da Terra Indígena, pode ser realizada a partir de indicadores sobre a condição de vida dos indígenas no Nordeste: alfabetização e rendimento.

Neste texto, mais especificamente, são apresentados os seguintes indicadores: o nível de alfabetização do povo indígena e o rendimento (medida da pobreza monetária).

Quadro 2 - taxa de alfabetização das pessoas de 15 anos ou mais de idade

\begin{tabular}{|c|c|c|c|c|c|c|c|c|c|}
\hline \multirow[t]{3}{*}{ Grandes Regiões } & \multicolumn{9}{|c|}{$\begin{array}{l}\text { Taxa de alfabetização das pessoas de } 15 \text { anos ou mais de idade, por condição de } \\
\text { indígena e situação do domicílio }\end{array}$} \\
\hline & \multicolumn{3}{|l|}{ Total } & \multicolumn{3}{|c|}{ Urbana } & \multicolumn{3}{|l|}{ Rural } \\
\hline & 1991 & 2000 & 2010 & 1991 & 2000 & 2010 & 1991 & 2000 & 2010 \\
\hline \multicolumn{10}{|c|}{ Indígenas } \\
\hline Brasil & 49,2 & 73,9 & 76,7 & 75,2 & 86,2 & 88,1 & 37,6 & 54,5 & 66,6 \\
\hline Nordeste & 40,6 & 74,3 & 76,4 & 68 & 83,7 & 84,6 & 26,3 & 54 & 65,5 \\
\hline \multicolumn{10}{|c|}{ Não indígenas } \\
\hline
\end{tabular}




\begin{tabular}{|l|l|l|l|l|l|l|l|l|l|}
\hline Brasil & 80,7 & 87,1 & 90,4 & 86,3 & 90,3 & 92,7 & 60,8 & 71,9 & 77 \\
\hline Nordeste & 63,5 & 75,2 & 81 & 74,6 & 81,6 & 85,7 & 44,3 & 59,3 & 67,2 \\
\hline
\end{tabular}

Fonte: BRASIL, 2010.

No quadro 2 vê-se a taxa de alfabetização das pessoas de 15 anos ou mais de idade por condição de indígena e situação do domicílio. Esse quadro mostra que o indígena residente no Brasil detém nível educacional mais baixo que aquele da população não indígena. O significativo aumento entre as taxas de alfabetização no período 1991/2000 foi devido, sobretudo, ao aumento de declarações de indígenas na área urbana em 2000 de acordo com IBGE (BRASIL, 2010).

Importante ressaltar que na região Nordeste, a taxa de alfabetização entre indígenas vem aumentando na área urbana de 1991-2010 mais que na área rural, podendo representar a necessidade de ampliação da oferta do ensino escolar para área rural. Quando se comparam as taxas de alfabetização com os "não indígenas", considerando somente as pessoas que se declararam indígenas em todas as Grandes Regiões em particular no Nordeste, as discrepâncias ainda são grandes.

O Registro Civil de Nacimento (RCN) não é obrigatório para indígenas, porém o acesso ao RCN como documentação básica, possibilita o acesso de indígenas aos direitos sociais comuns no país: direitos trabalhistas, previdenciários, acesso a crédito e programas sociais $^{10}$.

Quadro 3 - registro de nascimento do povo indígena até 10 anos de idade

\begin{tabular}{|l|c|c|c|}
\hline \multirow{2}{*}{$\begin{array}{c}\text { Percentual de pessoas indígenas até } \mathbf{1 0} \text { anos de idade com registro de nascimento - Brasil-2010 } \\
\text { Brasil e grandes } \\
\text { regiões }\end{array}$} & \multicolumn{3}{|c|}{ Com alguns tipos de registro de nascimento } \\
\cline { 2 - 4 } & \multirow{2}{*}{ Total } & \multicolumn{2}{c|}{ Tipo de registro de nascimento } \\
\cline { 2 - 4 } & & $\begin{array}{c}\text { Registro de } \\
\text { cartório }\end{array}$ & $\begin{array}{c}\text { Registro Administrativo de Nascimento } \\
\text { Indígenas (RANI) }\end{array}$ \\
\hline Brasil & 93.5 & 69.6 & $\mathbf{2 2 . 7}$ \\
\hline Norte & 88.2 & 65.4 & 21.2 \\
\hline Nordeste & 98.5 & 93.4 & 3.8 \\
\hline Sudeste & 99.1 & 92.8 & 5.7 \\
\hline Sul & 97.8 & 67.0 & 30.3 \\
\hline Centro Oeste & 98.2 & 46.3 & 51.1 \\
\hline
\end{tabular}

Fonte: IBGE (2010).

${ }^{10}$ BRASIL. Ministério da Justiça. Registro Civil de Nascimento para os povos indígenas no Brasil. Secretaria de Direitos Humanos; Fundação Nacional do Índio. Brasília, 2014. 
De acordo com o Censo do IBGE (BRASIL, 2010) o percentual de pessoas indígenas de até 10 anos de idade com Registro Administrativo de Nascimento Indígena ${ }^{11}$ no Brasil é de $22,7 \%$, número menor que o tipo de registro em cartórios, correspondente à $69.6 \%$. No que diz respeito às grandes regiões, o Nordeste apresenta a menor taxa mais $(3,8 \%)$ em relação a outras grandes regiões do Brasil, considerando que o índice de registro em cartório tornou-se o número mais elevado do que em outras regiões do país, 93.4\%.

Quadro 4 - Rendimento

\begin{tabular}{|c|c|c|c|c|}
\hline \multirow{3}{*}{ Regiões } & \multicolumn{4}{|c|}{$\begin{array}{l}\text { Proporção das pessoas indígenas de } 10 \text { anos ou mais de idade com até } 1 \\
\text { salário-mínimo e } \\
\text { sem rendimento nominal mensal, por localização do domicílio }\end{array}$} \\
\hline & \multicolumn{2}{|c|}{ Até 1 salário mínimo } & \multicolumn{2}{|c|}{ Sem rendimento nominal mensal } \\
\hline & $\begin{array}{l}\text { Nas Terras } \\
\text { Indígenas }\end{array}$ & $\begin{array}{l}\text { Fora das } \\
\text { Terras } \\
\text { Indígenas }\end{array}$ & $\begin{array}{l}\text { Nas Terras } \\
\text { Indígenas }\end{array}$ & $\begin{array}{l}\text { Fora das Terras } \\
\text { Indígenas }\end{array}$ \\
\hline Brasil & 27,9 & 32,8 & 65,8 & 39,5 \\
\hline Nordeste & 36,5 & 40,3 & 58,0 & 40,0 \\
\hline Pernambuco & 40,0 & 38,00 & 55,0 & 44,0 \\
\hline
\end{tabular}

Fonte: BRASIL, 2010.

A proporção das pessoas indígenas de 10 anos ou mais de idade sem rendimento nominal mensal, por localização do domicílio nas Terras Indígenas é mais elevada que fora das Terras Indígenas, respetivamente no Brasil, no Nordeste e em Pernambuco.

Os baixos indicadores de renda, presentes nos dados oficiais enquanto indicadores de pobreza podem não se aplicar a todas as populações tradicionais, ribeirinhas, pesqueiras, isoladas ou com poucos contatos com a sociedade nacional. Existem sociedades indígenas que vivem peculiarmente com uma relação direta com a terra, com os rios, com as florestas, com o manuseio independente do cultivo de seus bens coletivos, seus alimentos, quando dispõem de fartos recursos naturais. Podemos encontrar casos onde ainda há contatos com fartos bens naturais: água potável, peixes, terras férteis, boas condições climáticas, riqueza

${ }^{11}$ O Registro Administrativo de Nascimento de Indígena (RANI) é um documento administrativo fornecido pela Funai, instituído pelo Estatuto do Índio, Lei no 6.001 de 19 de dezembro de 1973: "O registro administrativo constituirá, quando couber, documento hábil para proceder ao registro civil do ato correspondente, admitido, na falta deste, como meio subsidiário de prova". Em outras palavras, o RANI pode servir como documento para solicitar o registro civil. O registro do RANI é realizado em livros próprios por funcionários da Funai, e para cada registro é emitido o documento correspondente, devidamente autenticado e assinado. O RANI é um documento administrativo e não substitui a certidão de nascimento. FUNAI, Fundação Nacional do Índio. Registro Administrativo de Nascimento de Indígena - RANI. 2021. Disponível em: https://www.gov.br/funai/pt-br/atuacao/povos-indigenas/direitos-sociais/registro-administrativo-denascimento-de-indigenarani\#: :text=0\%20Registro\%20Administrativo\%20de\%20Nascimento,civil\%20do\%20ato\%20correspondente\% 2C\%20admitido. 
da biodiversidade, da flora e da fauna. Nos casos de grupos étnicos que já mantêm contato com não indígenas, podem surgir outras demandas nessa interação. Ou seja, o levantamento e sistematização de dados sobre pobreza devem constar realidades de acesso e não acesso a recursos naturais necessários à continuidade, produção e reprodução social e humana, nos casos de ausência monetária e de renda.

Considerando as situações de não acesso farto aos recursos naturais e a impossibilidade de uma vida autônoma para produção dos meios básicos de reprodução social, por escassez de recursos naturais resultantes de mudanças climáticas, e da exploração predatória de grandes empreendimentos econômicos, as condições de permanência dos povos indígenas em seus territórios de origem são afetadas, ocorrendo migrações para outros territórios.

Como bem sistematiza Yazbek, a partir de análise dos dados do IBGE (BRASIL 2010), as pessoas que se encontram em situação de extrema pobreza são:

\begin{abstract}
Conforme dados apresentados no plano Brasil sem Miséria, a absoluta maioria dessas pessoas $(70,8 \%)$ é negra (pardas e pretas). Entretanto, chama a atenção a presença de indígenas, apesar de representarem, comparativamente, uma pequena parcela da população em situação de extrema pobreza. Os indígenas totalizam 817.963 pessoas no país, sendo que 326.375 se encontram em extrema pobreza, representando praticamente quatro em cada dez indígenas (39,9\%). Quanto ao sexo, que há uma distribuição homogênea entre homens e mulheres, com leve superioridade da presença feminina (50,5\% contra 49,5\%). Metade dos que vivem na pobreza extrema tem até 19 anos (50,9\%). As crianças até 14 anos representam cerca de quatro em cada dez indivíduos em extrema pobreza no Brasil (39,9\%) (YAZBEK, 2012, p. 314).
\end{abstract}

Entre os dados apresentados, 39\% dos indígenas do Brasil estão no grupo das pessoas que se encontram em situação de extrema pobreza. Dentro dos parâmetros de extremas restrições para sobreviver ${ }^{12}$.

A avaliação das condições de extrema pobreza dos documentos apresentados faz referência aos principais elementos necessários à produção e reprodução da vida humana: água, educação, saneamento básico e renda.

\footnotetext{
12 Os critérios de identificação desse grupo entre os sem rendimentos foram os seguintes: "1. Sem banheiro de uso exclusivo; ou, 2. Sem ligação com rede geral de esgoto ou pluvial e não tinham fossa séptica; ou, 3. Em área urbana sem ligação à rede geral de distribuição de água; ou, 4. Em área rural sem ligação à rede geral de distribuição de água e sem poço ou nascente na propriedade; ou, 5. Sem energia elétrica; ou, 6 . Com pelo menos um morador de 15 anos ou mais de idade analfabeto; ou, 7. Com pelo menos três moradores de até 14 anos de idade; ou, 8. Pelo menos um morador de 65 anos ou mais de idade" (YAZBEK, 2012, p. 314).
} 
Sem água não há possibilidade de viver bem, de produzir, não há segurança alimentar no campo e na cidade. Sem renda e alfabetização, a interação, as inserções no mercado de trabalho na vida urbana tendem ser precárias.

Importante destacar que dos últimos 30 anos do século $X X$ ao início do século XXI ocorrem muitas mudanças em termos normativos referentes à relação entre povos indígenas, o Estado e a sociedade brasileira. O avanço do Movimento Indígena representa um importante instrumento reivindicativo em favor dos povos originários.

Considera-se que o acesso à educação escolar ainda é um desafio. Mesmo com a ampliação da oferta de ensino escolar hoje existente em algumas aldeias do Brasil, resultantes da demanda dos povos indígenas por uma educação diferenciada que respeite a cultura e os costumes dos povos originários, ainda há muito trabalho pela frente. Especialmente, a construção de estratégias que garantam uma educação intercultural, baseada no respeito e na construção de cidadanias multiétnicas. Tudo isso exige o fortalecimento da inserção de uma geração de indígenas nas universidades e políticas públicas que promovam igualdade de acesso para os povos indígenas.

\section{Considerações finais}

Importante destacar nos últimos 30 anos do final do século $X X$ ao início de século XXI ocorrem muitas mudanças em termos normativos referentes à relação entre povos indígenas, Estado e sociedade brasileira, expressando o avanço das conquistas do Movimento Indígena e representam a disposição de um instrumento reivindicativo em favor dos povos originários.

O acesso à educação escolar é um direito fundamental. A oferta de educação escolar diferenciada nos territórios indígenas, em um conjunto de aldeias do Brasil, é resultado da luta do Movimento Indígena em suas diversas modalidades de organização, diante das demandas por uma educação diferenciada que respeite a cultura e os costumes dos povos originários. Ainda há muito trabalho pela frente no que ser refere à garantia do acesso à educação escolar indígena no espaço urbano, o respeito à pluralidade e diferença étnica.

Destaca-se a necessidade de construção e fortalecimento de políticas públicas que possibilitem a vida, o trabalho indígena em seus territórios de origem. Na cidade, estratégias 
que garantam uma educação baseada no respeito à integridade das diferentes identidades, crenças, valores e tradições étnicas, fortalecimento de políticas públicas de inserção de uma geração de indígenas nas universidades associadas às políticas sociais para povos indígenas que garantam o direito à terra, ao território e proteção das condições ambientais dos ecossistemas onde vivem e resistem os povos originários.

\section{Referências}

ARRUTI, José Maurício. A situação no Nordeste. Disponível em: https://pib.socioambiental.org/pt/c/no-brasil-atual/quem-sao/a-situacao-no-nordeste. Acessado em: 27 fev. 2017.

ARRUTI, José Maurício. ARRUTI, José Maurício. A tradição legalista e o forte senso comum sobre o que deve ser um índio (naturalidade e imemorialidade) têm funcionado como sérios obstáculos à implementação de avanços teóricos e jurídicos no reconhecimento de povos indígenas resistentes. In.: Povos Indígenas no Brasil: 2001-2005 I [editores gerais Beto Ricardo e Fany Ricardo]. - São Paulo: Instituto Socioambiental. 2006.

BRASIL. Ministério do Planejamento, Orçamento e Gestão Instituto Brasileiro de Geografia e Estatística - IBGE. Censo Demográfico 2010: Características gerais dos indígenas, Resultados do universo. ISSN 0104-3145 Censo demográfico., Rio de Janeiro, p.1- 245, 2010.

BRASIL. Ministério da Justiça. Registro Civil de Nascimento para os povos indígenas no Brasil. Secretaria de Direitos Humanos; Fundação Nacional do Índio. Brasília, 2014.

FUNAl. Fundação Nacional do Índio. Terras indígenas: o que é? Disponível em: <http://www.funai.gov.br/index.php/nossas-acoes/demarcacao-de-terras-indigenas>: acessado em: 26 de agosto de 2018.

OLIVEIRA, João Pacheco de. "A viagem da volta": reelaboração cultural e horizonte político dos povos indígenas no Nordeste. In.: Atlas das terras indígenas no Nordeste. Projeto Estudos Indígenas no Brasil. PETI, Museu Nacional, UFRJ, 1993.

SILVA, Edson. Povos indígenas no Nordeste: uma contribuição a reflexão histórica sobre os processos de resistência, afirmação e emergência étnica. ANPUH - XXII SIMPÓSIO NACIONAL DE HISTÓRIA - João Pessoa, 2003.

SILVA, Edson Hely. Índios no Nordeste: por uma história socioambiental regional. Cadernos do Ceas. Salvador/Recife, n. 240, p. 117-136, jan./abr., 2017 | ISSN 2447-861X.

SILVA, Elizângela Cardoso de Araújo. Indígenas Pankararu no sertão de Pernambuco: vida, deslocamentos e trabalho. Tese (Doutorado em Serviço Social) - Universidade Federal de Pernambuco, CCSA, 2020. 222 folhas: il. $30 \mathrm{~cm}$. 
TELLES, Vera Silva. A cidade nas fronteiras do legal e ilegal. - Belo Horizonte, MG: Fino Traço, 2010.

YAZBEK, Maria Carmelita. Classes subalternas e assistência social. 7. ed. São Paulo: Cortez, 2009.

YAZBEK, Maria Carmelita. Pobreza no Brasil contemporâneo e formas de seu enfrentamento. Serv. Soc. Soc. [online]. 2012, n.110, pp.288-322. ISSN 0101-6628

Documentários:

Índios na cidade. Vídeo disponível em: <https://www.youtube.com/watch?v=MOmrQZ5/qB4>. Publicado em 08 de agosto de 2013. Acessado em: 26 de agosto de 2018.

Índios na cidade, vidas em travessia. Documentário da TV Universitária, exibido no dia 19 de abril de 2014, na TV Brasil. <https://www.youtube.com/watch?v=S81xFIHRnok> Publicado em 31 de julho de 2014. Acessado em: 26 de agosto de 2018.

Recebido em: 04.04. 2020

Aceito em: 22.06.2021 